\title{
Assessment of Requirements for Successful Mobile Project Management Information Systems
}

\author{
Ung-Kyun Lee ${ }^{1 *}$ Hyung Seok "David" Jeong ${ }^{2}$ Asregedew Woldesenbet ${ }^{2}$ \\ Division of Architecture, Kwandong University, Gangneung-si, Gangwon-do 210-701, Korea ${ }^{1}$ \\ Department of Civil, Construction and Environmental Engineering, Iowa State University, Ames, IA 50011, USA ${ }^{2}$
}

Abstract

The objective of this study is to assess the requirements of tablet PC-based PMIS applications designed for use on construction sites to determine whether these new programs can play a significant role in increasing the efficiency of a project. In this research, the current market conditions of PMIS running on a tablet PC were analyzed. In addition, two industry surveys were conducted. A research team interviewed some industry experts and identified fourteen useful and desirable functions that can be incorporated into tablet PC-based applications and project management tools. Through a questionnaire survey, the most effective functions for the tablet PC-based PMIS were identified. The three top-rated functions among those suggested were Contact Information for Job-Related Personnel; Receive and Respond to Submittals, RFIs, and Notices; and Problem Solving for Design and Engineering Issues. The results of this research are expected to provide helpful information for mobile application developers and members of other interested groups in the construction industry.

Keywords : project management information system, tablet PC, smartphone

\section{Introduction}

In the construction industry, information must be transferred and exchanged during the project lifecycle. In recent years, a variety of technologies have been widely applied at different levels to achieve this. However, team members sometimes have difficulty accessing information related to a project. A high level of management is also required to prevent interference and confusion among the project personnel. Moreover, many bulky drawings and documents often must be carried onto construction sites, which is inconvenient for project members.

Received : September 27, 2013

Revision received : November 14, 2013

Accepted : November 18, 2013

* Corresponding author : Ung-Kyun Lee

[Tel: +82-33-649-7548, E-mail: uklee@kd.ac.kr]

(c)2014 The Korea Institute of Building Construction, All rights reserved.
These issues may affect the project in terms of quality, quantity, and scheduling. Nevertheless, paper files and paper-based tasks are still the most popular means of transferring and exchanging primary information on construction sites. This may be because project members are unaware of the efficiency and convenience that modern devices have introduced to the construction industry. Moreover, most of them may be accustomed to using conventional forms of data transfer during the different stages of a project, and they may assume that reeducating themselves is expensive in terms of time and money. They certainly ignore the negative outcomes of downtime, reconstruction work, waste, and cost overruns that result from inaccurate and inefficient interactions between team participants. The cost and the time needed to reeducate team members may be far less than that lost by continuing to use conventional 
methods of information conveyance. As such, there is a need to introduce the use of project management information system (PMIS) applications for new and cleverly designed devices (such as tablet PCs) in the construction industry to increase the speed and efficiency of data transfer in a project.

The objective of this study is to assess the requirements and efficiency of tablet PC-based PMIS applications for use on construction work sites. For this reason, the functions available in PMIS-based construction project management tools that are useful and desirable for effectively handling project management issues in the field have been identified.

\section{Review of literature and tablet PC-based PMIS applications}

\subsection{Overview}

A PMIS is an information system for gathering, integrating, and disseminating the output of project management processes among project participants[1]. A number of project management software programs have been developed, and their capabilities include scheduling and planning, estimation and cost control, quality management, resource allocation, communications, and documentation or administration systems. As shown in Table 1, three types of web-based applications have been developed for the architectural, engineering, and construction (AEC) industry: fee-based project management services, build-it-yourself solutions, and web-enabled software[2,3]. The first type is offered by application service providers (ASPs), and is a fee-based project management service provided by a professional IT company. The benefits of such a service include low implementation cost, low IT-expertise requirements, easy application upgrade, and simple system requirements. The limitation of using an ASP is that information might be under third party control, so information security, data accessibility, and service quality are major concerns. The second type, called build-it-yourself solutions, is suitable for extremely large companies. These applications can be custom built to the business environment, thus allowing businesses to maintain their own business style. Some limitations of this solution are the significant investment cost, outsourcing, and a long development cycle. The last type is web-enabled software, and refers to whole-set web-based software that is bought and maintained by construction companies. The third solution is a compromise between the former two. It reduces the need for outsourcing and shortens the development cycle, while keeping sensitive information under the supervision of in-house technical staff. Its limitations are its higher initial cost and the greater amount of expertise required of the staff[2]. Among the three types of applications mentioned above, the first type, web-based applications, has gained more popularity in the AEC industry, because it requires minimal technical, financial, and human resources for development and operation[4].

Because the use of the Internet has become more widespread in the construction industry, a collaborative system has been developed that can simultaneously support multiple users and allow them to modify different sections of a plan. Project management information tools allow team members to check their (and others') schedules and work on them offline, while allowing others to access information on a read-only basis. When reconnecting to the database, all changes are synchronized with the other schedules. These functions can be exploited using mobile devices, such as smartphones and tablet PCs, so the usage of mobile devices is increasing in the AEC industry.

In this section, tablet PC-based applications for construction projects are reviewed to help users understand the current status of this field and show 
the direction of their development in the construction industry.

Table 1. Features of web-based applications

\begin{tabular}{|c|c|c|}
\hline $\begin{array}{c}\text { Types of } \\
\text { applications }\end{array}$ & Features & Benefits \\
\hline ASPs & $\begin{array}{l}\text { Subscription required } \\
\text { Project management } \\
\text { services are provided by } \\
\text { professional } \\
\text { companies } \\
\text { Sensitive information } \\
\text { would be under } \\
\text { third-party control }\end{array}$ & $\begin{array}{l}\text { Low implementation cost } \\
\text { Low IT-expertise } \\
\text { requirements } \\
\text { Easy application } \\
\text { upgrade } \\
\text { Simple system } \\
\text { requirements }\end{array}$ \\
\hline $\begin{array}{l}\text { Build-it-you } \\
\text { rseelf } \\
\text { solutions }\end{array}$ & $\begin{array}{c}\text { Suitable for large } \\
\text { companies } \\
\text { Significant amount of } \\
\text { investment, outsourcing, } \\
\text { and a long development } \\
\text { cycle required }\end{array}$ & $\begin{array}{l}\text { Tailor-made applications } \\
\text { appropriate for business } \\
\text { environment Allow } \\
\text { businesses to maintain } \\
\text { their own style }\end{array}$ \\
\hline $\begin{array}{l}\text { Web-enabl } \\
\text { ed software }\end{array}$ & $\begin{array}{c}\text { Web-based software that } \\
\text { can be bought and } \\
\text { maintained by } \\
\text { construction companies } \\
\text { Higher initial cost and } \\
\text { greater amount of } \\
\text { expertise of the staff } \\
\text { required }\end{array}$ & $\begin{array}{l}\text { Reduced need for } \\
\text { outsourcing } \\
\text { Shorter development } \\
\text { cycle } \\
\text { Sensitive information } \\
\text { remains under the } \\
\text { supervision of the } \\
\text { in-house technical staff }\end{array}$ \\
\hline
\end{tabular}

\subsection{Mobile PMIS}

Traditionally, web-based PMISs, which are installed on desktop PCs, have many capabilities that support the management process in the construction industry. They can be used to set up a schedule, estimate a project budget, order procurements for a project, publish a report, and share all data via the Internet. Many desktop PMIS software applications have collaboration features that allow all data changes made by project members to be synchronized instantly, regardless of distance and time, via the Internet. Although these products can successfully support project stakeholders, such as superintendents or field engineers, the stakeholders cannot use them extensively because they cannot carry their desktop PC onto the work site. Therefore, fieldwork still depends on worker ability. They have to carry heavy drawings and related documents, create paper-based reports in the field, or retype reports on a computer in their office.

However, one of the advantages of mobile devices is their portability. In addition, highly efficient mobile devices whose performance is almost equal to that of PCs are creating some changes in this market. Construction projects typically take place in the field, where construction practitioners have difficulty in gaining access to conventional information systems. However, advances in affordable mobile devices, increases in the wireless network transfer speed (such as 4G), and performance enhancement of mobile applications can greatly improve on-site construction information management[5].

In addition, different mobile devices have their own specific characteristics as opposed to the desktop computer. For example, tablet PCs have a large display, a built-in digital camera, a microphone for recording voice, speakers, GPS, and a 3G, 4G, or Wi-Fi connection. Moreover, wireless Internet allows users to obtain data from and input their data into the central project management program. Thus, a tablet PC would be very helpful for on-site construction project management.

\subsection{Current well-known tablet PC applications}

The popular tablet PC-based applications for project management information systems that were found in U.S. application (app) stores were reviewed. To provide a better understanding, these applications are categorized into different stages in terms of their functionality in the construction industry: 1) design, 2) construction, 3) commissioning, and 4) management. In addition, the related subsections of each stage are shown in Table 2 . The design stage is further classified into three sections: 1) BIM application, 2) drawing, and 3) estimation applications. Most of the applications are allocated to the construction stage, which is classified into the following five categories: 1) construction, 2) construction forms for contractors, 3) documentation, 4) document viewing, and 5) work site monitoring. Commissioning and inspection make up the commissioning stage. In addition, for the management stage, only two categories (project management and safety management) are 
considered. The ultimate goal of identifying these new and useful applications, which are currently being used in the construction industry, is to help construction engineers to become familiar with them. In addition, the knowledge gained about the advantages of these applications may, hopefully, encourage them to utilize this new technology in their current or future projects.

Table 2. Tablet PC-based project management information system applications

\begin{tabular}{|c|c|c|}
\hline $\begin{array}{l}\text { Construction } \\
\text { project stages }\end{array}$ & Categories & Applications \\
\hline \multirow[t]{2}{*}{ Design } & $\begin{array}{c}\text { BIM applications } \\
\text { Drawings }\end{array}$ & $\begin{array}{c}\text { Buzzaw, BIMx, Go BIM } \\
\text { CADTouch R2, Finger CAD, } \\
\text { REVITKkeys, Irhino 3D, } \\
\text { AutoCAD WS }\end{array}$ \\
\hline & Estimations & $\begin{array}{l}\text { iQuick, Fast paint, } \\
\text { Job Estimator, Bid } \\
\text { landscaping }\end{array}$ \\
\hline \multirow[t]{5}{*}{ Construction } & Construction & $\begin{array}{c}\text { BüllderTrend, Plan room, M } \\
\text { penge project }\end{array}$ \\
\hline & $\begin{array}{l}\text { Construction } \\
\text { forms for } \\
\text { contractors }\end{array}$ & $\begin{array}{l}\text { Time and materials log, } \\
\text { Project closeout checklist, } \\
\text { Accident report Contractor's } \\
\text { App Box }\end{array}$ \\
\hline & Documentation & $\begin{array}{l}\text { Toodledo, Penultimate, } \\
\text { iAnnotate, Prontoforms }\end{array}$ \\
\hline & $\begin{array}{l}\text { Document } \\
\text { viewing }\end{array}$ & $\begin{array}{l}\text { iBlue print, } \\
\text { Drawvis\&turboviewer }\end{array}$ \\
\hline & $\begin{array}{l}\text { Work site } \\
\text { monitoring }\end{array}$ & $\begin{array}{c}\text { Control center } 7 \text {, Ustream } \\
\text { Broad caśter }\end{array}$ \\
\hline \multirow[t]{2}{*}{ Commissioning } & Commissioning & $\begin{array}{l}\text { Newforma's new punchlist, } \\
\text { Vela systems, Latista }\end{array}$ \\
\hline & Inspection & Smart Bidnet \\
\hline \multirow[t]{2}{*}{ Management } & $\begin{array}{l}\text { Project } \\
\text { management }\end{array}$ & $\begin{array}{l}\text { Procore construction, } \\
\text { Corecone mobile v7 }\end{array}$ \\
\hline & $\begin{array}{l}\text { Safety } \\
\text { management }\end{array}$ & SafetyNet \\
\hline
\end{tabular}

\subsection{Remarks}

In this section, a review of mobile and tablet $\mathrm{PC}$-based applications for construction projects is presented to help users understand the current status of this field and show the direction of its development in the construction industry. Mobile devices and work site conditions must be understood to develop a PMIS application for construction projects. Mobile devices cannot perform as desktop PCs do, and conditions on a construction site are also different from those in an office.

The following facts were identified through the review. Although many mobile-based applications have been used in the AEC industry, there is no specific category dedicated to the AEC industry in application stores. Therefore, users, such as project managers or field engineers, who can use a tablet PC effectively, conduct their work using various applications. They use existing applications to fulfill their purposes. In current field conditions, applications are most useful for inspection work. In fact, mobile devices render many other technologies unnecessary; users will not need a digital camera, level, calculator, or laptop. Depending on the application, a tablet PC can substitute for these devices.

Further, a compatible data format should be considered. All the documents or photos produced using a smartphone can be saved in the PDF or JPEG format. Even if a project member uses an application different from that which others use, the final results are in a common format.

Developers of a new type of PMIS are recommended to focus on a specific area of the system, and not the entire integrated one. To survive in this business environment, future developers of software for this PMIS should focus on specific items, such as the organization of punch lists for quality management or report applications for safety management.

\section{Industry survey}

\subsection{Overview}

In this study, two industry surveys were conducted: interviews with experts; i.e., current construction engineers who are using mobile-based applications, and a questionnaire survey to collect needed information from industry project practitioners. The questionnaire was designed using the results of the literature review and experts interview. In this section, a summary of the results of the two surveys is presented.

\subsection{Interview of industry professionals}

The research team interviewed project engineers, 
Table 3. Information of industry experts and PMIS software used

\begin{tabular}{|c|c|c|c|c|}
\hline \multirow{2}{*}{ Interviewee } & \multirow{2}{*}{ Position } & \multirow{2}{*}{ Construction company } & \multicolumn{2}{|c|}{ Purpose of PMIS implementations } \\
\hline & & & Desktop-based applications & Mobile applications \\
\hline$A$ & Project engineer & $\mathrm{F}$ & $\begin{array}{c}\text { Scheduling } \\
\text { Cost tracking and accounting }\end{array}$ & $\begin{array}{c}\text { Scheduling } \\
\text { Quality control }\end{array}$ \\
\hline B & Estimator & $S$ & $\begin{array}{c}\text { Scheduling } \\
\text { Cost tracking and accounting }\end{array}$ & $\begin{array}{c}\text { Bidding and estimating purposes } \\
\text { Tracking on the site and resource } \\
\text { planning }\end{array}$ \\
\hline $\mathrm{C}$ & $\begin{array}{l}\text { President/project } \\
\text { manager }\end{array}$ & L & Scheduling & $\begin{array}{l}\text { Tracking overall cost and accounting } \\
\text { and changing orders and pricing using } \\
\text { the service management module }\end{array}$ \\
\hline $\mathrm{D}$ & Project superintendent & $\mathrm{H}$ & $\begin{array}{c}\text { Scheduling } \\
\text { Cost tracking and accounting }\end{array}$ & $\begin{array}{c}\text { Task management purposes, to organize } \\
\text { contacts, import pictures, pDFs and } \\
\text { drawings, and develop a mobile database } \\
\text { for as-built drawings } \\
\text { Taking screenshots of any work and } \\
\text { changing them into pictures } \\
\text { Quality control and management issues, } \\
\text { and checklists } \\
\text { Creating, opening, and editing Microsoft } \\
\text { office files }\end{array}$ \\
\hline
\end{tabular}

who had extensively used tablet PCs or mobile devices for construction project management in their previous or current projects. Every interviewee had experience in using a desktop-based PMIS, and one had been using a mobile-based PMIS for a construction project. The interviews were conducted from November 2011 to January 2012. There were four interviewees, and their positions were project engineer, estimator, president/project manager, and project superintendent. Table 3 shows detailed information about the interviewees and the PMIS software programs that they used.

Through meetings and interviews, it was found that these experts employ a wide variety of software and tablet PC-based applications for managing projects. They also suggested useful and desirable functions that can be incorporated into tablet PC-based applications and project management tools. These functions include 1) A function that converts voice records into text format for recording daily work reports (voice speech recognition system); 2) a function that integrates their accounting system with daily work reports; for example, a system that tracks production rates, such as the number of doors installed per day or reinforcements installed per linear foot of a beam; a documentation system to integrate the data collected from the field; 3) a function that can incorporate a camera for taking photographs and sending them to the responsible party, or storing them as part of documentation; 4) a scheduling mechanism to manage subcontractors and work tasks; and 5) a layering mechanism to visualize $2-\mathrm{D}$ and/or 3-D drawings. Therefore, these functions should be incorporated into tablet PC-based applications and project management tools to increase the productivity and effective handling of project management issues in the construction field.

\subsection{Questionnaire survey}

\subsubsection{Survey overview}

This survey was primarily conducted to identify useful and desirable functions that should be available in tablet PC-based construction project management tools to effectively handle project management issues on the field. From the literature review presented above, six main categories were obtained. Moreover, from the on-site interviews with experts, functions that are considered critical for mobile-based applications used for management of construction projects were analyzed. 
Table 4. Required functions in mobile-based applications

\begin{tabular}{|c|c|}
\hline Main categories & Subcategories \\
\hline Communication & $\begin{array}{l}\text { C1. Storage of Contact Information of } \\
\text { Job-Related Personnel } \\
\text { C2. Receive and Respond to Submittals, RFIs, } \\
\text { and Notices } \\
\text { C3. Speech Recognition }\end{array}$ \\
\hline $\begin{array}{l}\text { Quality } \\
\text { management }\end{array}$ & $\begin{array}{l}\text { QM1. Conduct Punch Lists } \\
\text { QM2. Conduct Punch Lists } \\
\text { QM3. Quality Assurance/Control } \\
\text { QM4. Quality Assurance/Control }\end{array}$ \\
\hline $\begin{array}{l}\text { Safety } \\
\text { management }\end{array}$ & $\begin{array}{l}\text { S1. Accident Prevention and Reports } \\
\text { S2. Potential Safety Accident Alert } \\
\text { S3. Scheduling of Safety Training and } \\
\text { Meetings }\end{array}$ \\
\hline $\begin{array}{l}\text { Environmental } \\
\text { issues }\end{array}$ & $\begin{array}{l}\text { E. Tracking of Environmental Permits, } \\
\text { Requirements, and Issues }\end{array}$ \\
\hline $\begin{array}{l}\text { Daily work } \\
\text { reports }\end{array}$ & D. Writing Daily Work Reports on Site \\
\hline $\begin{array}{l}\text { Design and } \\
\text { Engineering }\end{array}$ & $\begin{array}{l}\text { DE1. Access to Technical Engineering } \\
\text { Information on the Site } \\
\text { DE2. Problem Solving for Design and } \\
\text { Engineering Issues }\end{array}$ \\
\hline
\end{tabular}

Table 4 shows the functions required in mobile-based applications and their detailed descriptions. The functions are categorized into communication (with three subcategories), quality management (with two subcategories), safety management (with three subcategories), environmental issues, daily work reports, and design and engineering (with two subcategories).

\subsubsection{Survey participants}

The survey participants were members of the Associated General Contractors of America (AGC) and general contractors in Oklahoma. In Oklahoma, the survey form was provided to potential respondents as a hard copy. For the AGC members, a professional survey website (www.surveymonkey.com) was used. According to the SurveyMonkey website, in total, 356 survey forms were received.

\subsection{Survey results and analysis}

\subsubsection{General description}

Figures 1 and 2 show the response ratio depending on the construction industry sector and the job posi- tions of the respondents, respectively. As can be seen in Figure 1, 69.8\% of all responses are from the commercial construction sector whereas $37.3 \%, 20.0 \%$, and $6.5 \%$ are from the heavy civil, commercial, and residential building sectors, respectively.

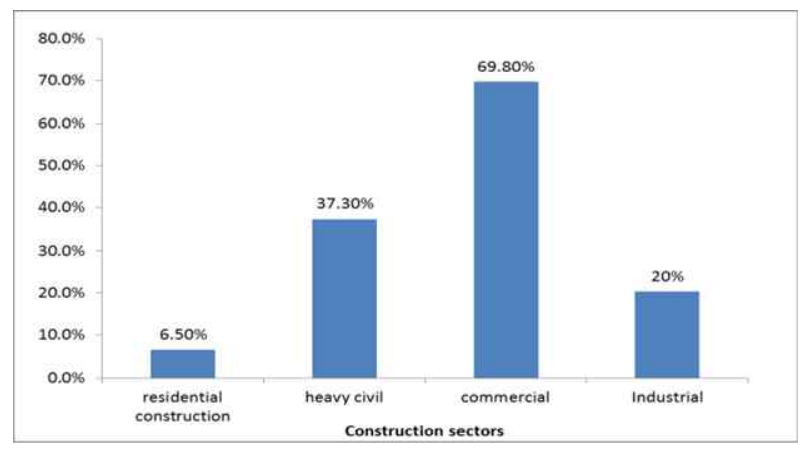

Figure 1. Types of construction industry

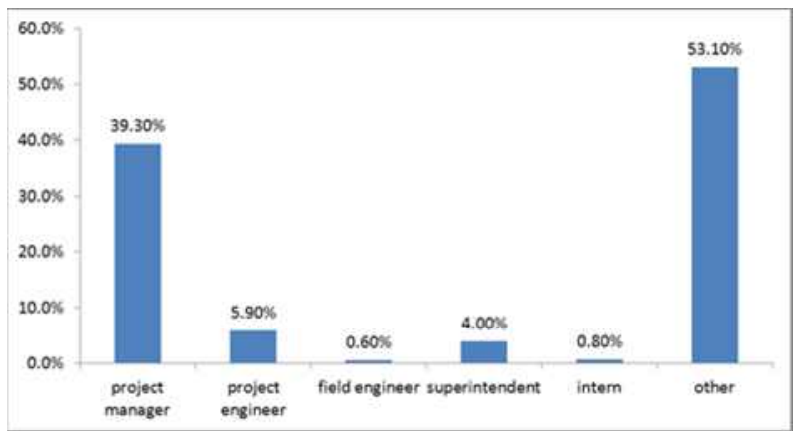

Figure 2. Positions of respondents

In the questionnaire, participants were also asked if they used any project management software programs for their projects. These programs were categorized into five groups: (1) desktop PC-based project management software programs, (2) tablet PC-based project management software programs (tools), (3) smartphone-based project management software programs (applications), (4) none of the above, and (5) other tools. From the results, which are shown in Figure 3, we can see that 92.2\% of the respondents prefer to use desktop PC-based programs whereas $85.5 \%$ and $84.4 \%$ prefer tablet $\mathrm{PC}$-based programs and smartphone-based programs, respectively, over other tools. However, $25.2 \%$ and $18.4 \%$ of respondents 
chose none of the mentioned tools and other programs, respectively.

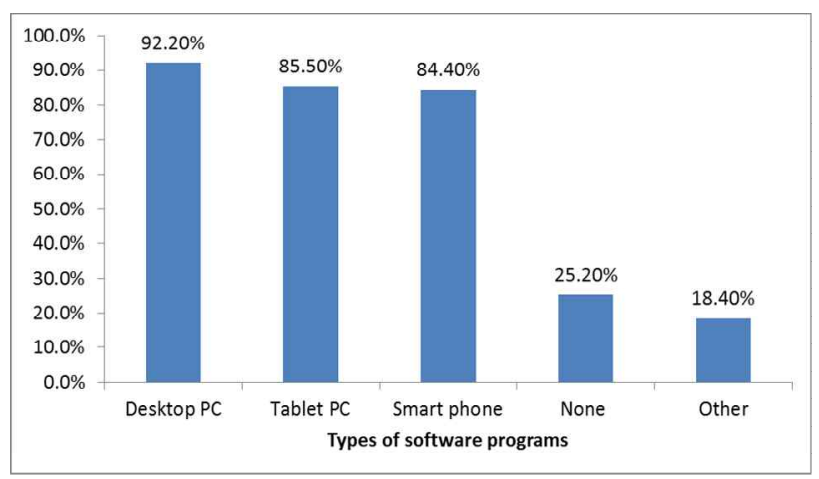

Figure 3. Types of project management software programs

\subsubsection{Degree of agreement of participants on tablet PC programs-based PMIS}

In this study, the participants' assessment of the degree of effectiveness of fourteen useful functions of tablet PC-based project management information systems was evaluated. Respondents were asked to rate the level of effectiveness of the functions of the tablet PC programs that are currently available in the construction field for their projects. They were asked to rate the effectiveness using a five-point Likert scale: "1 = Highly Ineffective, 2 = Useless, 3 = Moderately Useful, $4=$ Highly Useful, and 5 = Highly Effective."

Table 5 shows a summary of the responses to this survey. The contact information for job-related personnel (C1) communication feature was ranked by respondents as most effective, whereas the lowest level of effectiveness was related to another feature of communication, the speech recognition function of tablet PC programs (C3). These results indicate that the top three most effective functions are Contact Information for Job-Related Personnel (C1), Receive and Respond to Submittals, RFIs, and Notices (C2), and Problem Solving for Design and Engineering Issues (DE2). It is important to note that two of the top three functions are related to the communications feature of tablet PC programs, which indicates that currently, with the advent of new devices (such as tablet PCs and smartphones) that can be utilized in the construction industry, efficient communication is needed to improve the speed of information transmission between the site office, headquarters, and all the participants involved in a project.

In addition, most of the respondents indicated that this new technology might help construction industry personnel overcome many of the problems they face during different stages of a project. They do not perceive communication as problematic in the construction industry; however, they admit that communication processes are far from optimal. Wasted time was cited as a primary consequence of poor communication. For example, errors that occur in the early stages of a project have to be solved later. Moreover, making adjustments in the later stages of the building process usually incurs extra costs. Therefore, participants believed that improving communication by applying new and efficient systems would lead to fewer delays and lower expenses.

Table 5. Degree of effectiveness of tablet PC functions based PMIS

\begin{tabular}{ccc}
\hline \multirow{2}{*}{$\begin{array}{c}\text { Critical functions of tablet PC } \\
\text { programs-based PMIS }\end{array}$} & \multicolumn{2}{c}{ Degree of agreement } \\
\cline { 2 - 3 } & Rank & Mean \\
\hline C1 & 1 & 4.38 \\
C2 & 2 & 4.2 \\
C3 & 14 & 3.58 \\
QM1 & 7 & 3.97 \\
QM2 & 4 & 4.03 \\
QM3 & 8 & 3.82 \\
QM4 & 11 & 3.77 \\
S1 & 13 & 3.72 \\
S2 & 9 & 3.8 \\
S3 & 10 & 3.78 \\
E & 12 & 3.75 \\
D & 6 & 3.98 \\
DE1 & 5 & 3.99 \\
DE2 & 3 & 4.04 \\
\hline
\end{tabular}

As shown in Table 4, the other three desired functions are Conduct Punch Lists (QM2), Access to Technical Engineering Information on Site (DE1), and Writing Daily Work Reports on Site (D). Quality man- 
agement is an increasingly important concern for project managers because defects or failures in constructed facilities can result in very high costs. Even when minor defects occur, reconstruction may be required and a facility's operations may be impaired, resulting in increased costs and delays. Therefore, in terms of quality management, newly designed tablet PC programs are expected to help team members responsible for quality to quickly identify the location of a project's defects, thereby reducing cost and delays. Applications related to the Design/Engineering feature were rated as having a relatively high level of effectiveness by respondents because most of the design applications have been developed so that the design team can analyze projects, buildings, or structures without having to manually draw up plans or documents. Moreover, these applications have simplified the process of optimizing the costs and scheduling of a project's operations. In addition, design programs offer seamless integration with other software, and low-cost high-speed prototyping is in many ways changing the way design is being done, thus removing barriers to those wishing to enter this field.

The daily work report application function also received a high rating from the respondents. On the work site, field engineers and superintendents need to communicate with each other to adjust their work tasks. They need to write daily work reports and record site conditions. For instance, they need to record 1) the number of workers/employees, 2) the types of equipment used at the construction site, 3) the exact start and end times of work, 4) work progress, 5) weather conditions, 6) accidents, and 7) the number of crew members involved on the site. A daily work report application allows the responsible team members to avoid dealing with handwritten notes and documents and writing multiple daily reports. Therefore, if they are able to finish the daily report on the work site, the burden of work will be reduced. The average levels of agreement for the functions related to quality management, in terms of ensuring the quality of construction work, and safety management, including Accident Prevention and Reports (S1), Potential Safety Accident Alert (S2), Scheduling of Safety Trainings and Meetings (S3), and Environmental Issues (E), are very similar. However, functions related to communication in terms of speech recognition received the lowest level of agreement among the respondents. These results indicate that there is a perceived difference between the effectiveness of the fourteen tablet PC functions featured in PMISs.

\subsubsection{Other effective tablet PC functions}

Participants in the questionnaire survey were asked if there were other useful functions of tablet PC programs that were not included in the survey form. The results indicate that the top three effective functions are managing/tracking site activities, particularly inspections, communicating ideas by using simple drawing tools, e.g., the ability to view $\mathrm{CAD}$ and 3-D models, and keeping track of scheduling and time reporting of a project. It is important to note that these top three functions are classified in the construction and design tablet PC applications categories in the construction industry, which indicates the similarity of respondents' assessments concerning the most effective functions that are reported by the respondents and the questionnaire survey. Moreover, the results show that the "ability to access the central databases" and "BIM access for field use and cross communication between field and office/trades and designers" functions were ranked as having the same level of effectiveness as the other tablet $\mathrm{PC}$ functions.

The capability of tablet PC functions in controlling the cost of the project and the function "track daily production and digital takeoff" are other effective functions that were reported by the respondents in 
this survey. The high rankings given to these two functions indicate that at present, estimation functions have gained tremendous popularity in the construction industry. When asked why estimation applications are effective and popular in the construction industry, respondents stated that these types of applications "enable you to start" as soon as you hear about the project, adding that these applications meant it was no longer necessary to wait for prints or plots from the Architect or Engineers, saving time and improving accuracy.

\section{Conclusion}

With tablet PCs and mobile devices becoming more powerful, offering improved data storage capabilities and wireless connection abilities, a tablet PC-based PMIS is currently considered essential for a work site project management system. These mobile-based applications allow project engineers and managers to check and share the status of various project performances and upload various project data in real time. In this research, current market conditions of mobile based-PMISs running on a tablet PC were analyzed, and recommendations for setting the direction of their development were made on the basis of industry survey results.

For this study, two industry surveys were conducted. Through interviews with experts, the research team identified fourteen useful and desirable functions that can be incorporated into tablet PC-based applications and project management tools. Using these results, the questionnaire survey, in which members of the AGC and local general contractors participated, was designed with same purpose as the interviews with experts.

The results showed that the top three effective functions are Contact Information for Job-Related Personnel; Receive and Respond to Submittals, RFIs, and Notices; and Problem Solving for Design and Engineering Issues. However, the speech recognition communication function was given the lowest ranking by respondents.

This assessment can be useful to mobile application developers and other interested group members. For further research, a similar study with Korean contractors would be more helpful to developers.

\section{References}

1. Lee S, Yu J. Critical Success Factors for Project Management Information System in Construction. Journal of Construction Engineering and Project Management. 2011 May;1(1):25-30.

2. Zhu Y, Issa RRA, Cox RF. Web-based construction document processing via Malleable Frame. Journal of Computing in Civil Engineering. $2001 \mathrm{Jul} ; 15(3): 157-69$.

3. Nitithamyong P, Skibniewski MJ. Web-based construction project management systems: how to make them successful? Automation in Construction. 2004 Jul;13(4):491-506.

4. Thorpe T, Mead S. Project-specific web sites: friend or foe. Journal of Construction Engineering and Management. 2001 Oct;127(5):406-13.

5. Chen Y, Kamara JM. A framework for using mobile computing for information management on construction sites. Automation in Construction. 2011 Nov;20(7):776-88. 